\title{
KLF14 potentiates oxidative adaptation via modulating HO-1 signaling in castrate-resistant prostate cancer
}

\author{
Xiao-hui Luo1,*, Jian-zhou Liu1,*, Bo Wang1,*, Qun-li Men¹, Yu-quan Ju1, Feng-yan Yin¹, Chao Zheng' and Wei Li² \\ 1Department of Urology, Baoji Center Hospital, Baoji, Shaanxi Province, People's Republic of China \\ 2Department of Human Anatomy, Histology and Embryology, Fourth Military Medical University, Xi'an, Shaanxi Province, People's Republic of China
}

Correspondence should be addressed to X Luo or W Li: luoxiaohuidoctor@163.com or liweipepeyato@163.com

*(X Luo, J Liu and B Wang contributed equally to this work)

\begin{abstract}
Insights into the mechanisms by which key factors stimulate cell growth under androgendepleted conditions is a premise to the development of effective treatments with clinically significant activity in patients with castration-resistant prostate cancer (CRPC). Herein, we report that, the expression of Krüppel-like factor 14 (KLF14), a master transcription factor in the regulation of lipid metabolism, was significantly induced in castrationinsensitive PCa cells and tumor tissues from a mouse xenograft model of CRPC. KLF14 upregulation in PCa cells, which was stimulated upstream by oxidative stress, was dependent on multiple pathways including PI3K/AKT, p42/p44 MAPK, AMPK and PKC pathways. By means of ectopic overexpression and genetic inactivation, we further show that KLF14 promoted cell growth via positive regulation of the antioxidant response under androgen-depleted conditions. Mechanistically, KLF14 coupled to p300 and CBP to enhance the transcriptional activation of $H M O X 1$, the gene encoding the antioxidative enzyme heme oxygenase-1 (HO-1) that is one of the most important mechanisms of cell adaptation to stress. Transient knockdown of HMOX1 is sufficient to overcome KLF14 overexpression-potentiated PCa cell growth under androgen-depleted conditions. From a pharmacological standpoint, in vivo administration of ZnPPIX (a specific inhibitor of HO-1) effectively attenuates castration-resistant progression in the mouse xenograft model, without changing KLF14 level. Together, these results provide comprehensive insight into the KLF14-dependent regulation of antioxidant response and subsequent pathogenesis of castration resistance and indicate that interventions targeting the KLF14/HO-1 adaptive mechanism should be further explored for CRPC treatment.
\end{abstract}

\section{Key Words}

- Krüppel-like factor 14 (KLF14)

- CRPC

- oxidative stress

heme oxygenase-1 (HO-1)

- transcriptional regulation

\section{Introduction}

Worldwide, prostate cancer ( $\mathrm{PCa}$ ) is the most frequently diagnosed male cancer. About one-fourth of PCa patients eventually die from this disease. Because androgen receptor (AR) signaling is crucial for the development and maintenance of male reproductive organs including the prostate gland, men with PCa that has disseminated distantly usually respond well to androgen deprivation therapy (ADT) (either alone or in combination with
Endocrine-Related Cancer (2019) 26, 181-195 
chemotherapy). However, despite initial response rates of $\sim 80-90 \%$, nearly all PCa patients eventually develop progressive disease following ADT. This is referred to as castration-resistant prostate cancer (CRPC), an incurable stage in which $\sim 90 \%$ of patients develop metastases with the highest mortality rate (Ferraldeschi et al. 2015). Evidence from experimental and clinical studies have identified several potential mechanisms coexisting to confer CRPC, including deregulation of AR signaling (Zuo et al. 2016), activation of PI3K/AKT/mTOR pathway (Zhang et al. 2014b), perturbed lipid metabolism (Twiddy et al. 2011, Qi et al. 2013) and unbalanced oxidative stress (Shiota et al. 2011, Ning et al. 2016). In this scenario, continuous elucidation of the key molecules at different levels should strengthen our mechanistic understanding and provide valuable therapeutic guidance.

The Krüppel-like family of transcription factors (KLFs), containing 17 members and functioning as key modulators in embryogenesis and cell proliferation, differentiation and development, have recently received intensive investigations. KLFs possess highly conserved cysteine and histamine zinc fingers, recognizing and binding exclusively to the CACCC motifs (Guo et al. 2015). Despite their structural conservation, most KLFS engage in distinct cooperation or antagonism dependent upon the context (de Assuncao et al. 2014). Of particular interest, KLF14 has been identified by genetic studies to be a master trans-regulator of lipid metabolism (Civelek et al. 2017). A robust KLF14 expression has been tightly associated with obesity, type 2 diabetes (Bacos et al. 2016), breast and colon cancer (Fan et al. 2015). KLF14 can regulate lipid-mediated signaling through a distinct epigenetic mechanism (Fan et al. 2015). These studies have provided useful information regarding KLF14 function in metabolism. Considering the central involvement of KLF14 in lipid metabolism, we have focused on how KLF14 regulates the gene networks involved in lipid metabolism-related diseases. Thus, the current work aimed on defining a novel function for KLF14, involving transcriptional regulation induced by CRPC to expand our understanding of its role in metabolism regulation.

Through a combination of animal models, genetic tools and pharmacological means, we have uncovered a mechanistic role, reported here, for KLF14 in regulating the antioxidant response in CRPC by modulation of heme oxygenase-1 (HO-1) expression. Furthermore, we provide the functional evidence that in vivo administration of a pharmacological inhibitor of HO-1 could attenuate castration-resistant $\mathrm{PCa}$ progression. Overall, these findings demonstrate molecular mechanisms by which the KLF14/HO-1 cascade could serve as a promising therapeutic target for CRPC.

\section{Materials and methods}

\section{Cells treatment}

Human PCa cell lines (LNCaP, CWR-R1, 22RV1, PC3 and DU145) and normal human prostate cell RWPE-1 were obtained from American type culture collection (ATCC). All cells used for the current study were authenticated in October 2015 by STR DNA Profiling Analysis (Promega) and had less than 25 passages. RWPE- 1 cells were cultured in keratinocyte serum-free medium (Thermo Fisher Scientific) supplemented with $50 \mathrm{mg} / \mathrm{mL}$ bovine pituitary extract, $5 \mathrm{ng} / \mathrm{mL}$ epidermal growth factor, $100 \mathrm{U} / \mathrm{mL}$ penicillin and $100 \mathrm{U} / \mathrm{mL}$ streptomycin (GIBCO). Other PCa cells were routinely cultured in RPMI-1640 medium supplemented with $10 \%$ FBS (GIBCO) in a $37^{\circ} \mathrm{C}, 5 \% \mathrm{CO}_{2}$ incubator. To establish castration-resistant LNCaP sublines (designated as LNCaP-R), LNCaP cells were maintained in media containing $10 \%$ charcoal-stripped FBS (FBS-CS, GIBCO) in the presence of $10 \mu \mathrm{M}$ bicalutamide (SigmaAldrich) for 4 months, followed by measurement of intracellular prostate-specific antigen (PSA) and AR concentrations using commercially available ELSIA kits (Abcam), as described elsewhere (Ning et al. 2016). To study the effects of oxidative stress on KLF14 expression, PCa cells were incubated with $\mathrm{H}_{2} \mathrm{O}_{2}$ or diamide for various concentrations, in the presence or absence of $20 \mu \mathrm{mol} / \mathrm{L}$ diphenyleneiodonium chloride (Sigma-Aldrich) for different durations, as indicated. To stably knockdown the endogenous expression of KLF14, CWR-R1 and DU145 cells were transfected with pRS-KLF14 shRNA or Scramble shRNA (OriGene, Beijing, China) using ViaFect (Promega). One day after transfection, the transfected cells were selected with $1.0 \mu \mathrm{g} / \mathrm{mL}$ puromycin (Sigma-Aldrich) for 1-2 weeks. To overexpress the exogenous KLF14, LNCaP cells were transfected with pcDNA3.1+-DDK-KLF14 or pcDNA3.1+ vector (GenScript, Nanjing, China) using ViaFect, followed by Geneticin selection $(200 \mu \mathrm{g} / \mathrm{mL}$; Invitrogen) according to the manufacturer's instructions. To study the signal transduction pathways involved in oxidative stress-dependent KLF14 induction, PC3 cells were incubated with $1 \mathrm{mmol} / \mathrm{L}$ of $\mathrm{H}_{2} \mathrm{O}_{2}$ in the presence of different pathway inhibitors as indicated for $15 \mathrm{~min}$.

\section{CRPC patient-derived xenograft model}

The study protocol, strictly following the ethical standards of Helsinki Declaration, was approved by the Ethics 
Committee of Baoji Center Hospital. Written informed consent was obtained from the participant. Local recurrent PCa tumors were obtained from a 62-year-old patient who died of CRPC. The tissues were harvested after radical prostatectomy and were minced into $20-30 \mathrm{~mm}^{3}$ tumor bits, and transplanted subcutaneously into 5-week-old male nude mice, with $50 \mu \mathrm{L}$ Matrigel (BD Biosciences, Shanghai, China) surrounding the tumors. The xenografts were maintained for about 10 months. Subsequently, the transplantable xenografts were harvested and transplanted to several mice without Matrigel. After the xenografts grew to $\sim 120 \mathrm{~mm}^{3}$, the mice were surgically castrated (Terada et al. 2010). Tumor volume changes were recorded every week by two perpendicular diameter measurements.

\section{Cell proliferation}

CWR-R1 and DU145 cells with different transfections were plated onto a 96-well plate at $1 \times 10^{4}$ cells/well in media containing either 10\% FBS or 10\% FBS-CS (Invitrogen). After a 3-day culture, viable cell numbers were determined using Trypan blue staining (Invitrogen) along with hemocytometer count (Beckman Coulter).

\section{Cell apoptosis}

PCa cells with different transfections were cultured in media containing either 10\% FBS or 10\% FBS-CS for 3 days, followed by measurement of apoptosis using an apoptosis ELISA kit (Roche Diagnostics), as per the manufacturer's instructions. Cell apoptotic values were normalized to FBS-treated control cells.

\section{Colony formation assay}

PCa cells with different transfections were plated onto a 96-well plate at 400 cells/well and cultured in media containing either $10 \%$ FBS or $10 \%$ FBS-CS. When cell colonies were large enough to be clearly discerned around 14 days, the colonies were stained by a solution containing $0.5 \%$ crystal violet plus $25 \%$ methanol for $5 \mathrm{~min}$. The colonies were then scored using a laboratory automatic colony counter (Biobase Biotech, Jinan, China).

\section{In vivo tumor growth assay}

Tumor growth in nude mice was performed according to a previously established protocol (Yu et al. 2013). PCa cells with different transfections were injected into left flanks of castrated male nude mice. The inoculated cells were allowed to grow for 6 weeks until the tumors reached a volume of $\sim 100-250 \mathrm{~mm}^{3}$ for CWR-R1 and DU145 cells, and of $\sim 20 \mathrm{~mm}^{3}$ for LNCaP cells, respectively. Tumor volume changes were recorded every week by two perpendicular diameter measurements and were calculated with formula $0.5236 \times r 1^{2} \times r 2$ (where $r 1<r 2$ ) (Long et al. 2000). All procedures involving animals, strictly conformed to the Guide for the Care and Use of Laboratory Animals, were approved by the ACUC of Baoji Center Hospital.

\section{Cell viability assay upon oxidative stress}

Subconfluent proliferating LNCaP and DU145 cells in 96-well plates were stimulated with different doses of $\mathrm{H}_{2} \mathrm{O}_{2}$ or paraquat (Sigma-Aldrich) for different time intervals as indicated, followed by measurement of cell viability using CellTiter-Blue Reagent (Promega) and of GSH/GSSG ratio using a commercial GSH/GSSG Ratio Detection Assay Kit (Abcam), according to the manufacturer's instructions. Cell viability values were normalized to 0 dose Ctrl cells.

\section{Promoter reporter assay}

For the assessment of $H M O X 1$ promoter activity, the genomic fragments harboring the putative KLF14-binding sites in human HMOX1 promoter $(\sim 1.8 \mathrm{~kb}$ upstream of the translation start site) were subcloned into the pGL4-Luc reporter vector (Promega) using Infusion 2.0 Dry-Down PCR cloning kit (Clontech, Shanghai, China). Promoter activity was further validated by mutation of the putative KLF14-binding site on the promoter at $-406 /-402$ by replacing CACCC with CAaaa using the QuikChange Site-Directed Mutagenesis Kit (Agilent). For reporter assay, $0.5 \mu \mathrm{g}$ reporter plasmid and pRL-TK Renilla reporter plasmid were co-transfected with pcDNA3.1+-DDK-KLF14 or pcDNA3.1+ vector into HeLa cells using FUGENE. $48 \mathrm{~h}$ later, cells were treated for $15 \mathrm{~min}$ with $1 \mathrm{mmol} / \mathrm{L}$ of $\mathrm{H}_{2} \mathrm{O}_{2}, 30 \mathrm{mmol} / \mathrm{L}$ of diamide or diamide plus $20 \mu \mathrm{mol} / \mathrm{L}$ of diphenyleneiodonium chloride, followed by luciferase activity measurements using a dual luciferase reporter assay kit (Promega).

\section{RT-qPCR}

Total RNA extraction, reverse transcription and PCR were carried out as described previously (Dong et al. 2016). Routine DNase (Applied Biosystems/Ambion) treatment

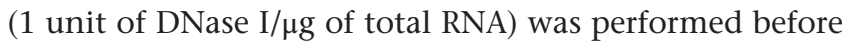
RT. The primers used were listed in Supplementary Table 1 (c) 2019 Society for Endocrinology Published by Bioscientifica Ltd. Printed in Great Britain 
(see section on supplementary data given at the end of this article). PCR products were subsequently quantified by SYBR Green intercalation using the MiniOpticon system (Bio-Rad). Relative expression levels from three independent experiments were determined using $2^{-\Delta \Delta \mathrm{Ct}}$ method (Zhang et al. 2014a).

\section{Immunoblotting}

Total protein from PCa cells and xenografts was isolated using Chemicon Total Protein Extraction Kit (Merck Millipore), and protein concentrations were determined by a protein assay kit (Bio-Rad). Immunoblotting was carried out as described previously (Li et al. 2014). The antibodies used for the current study were listed in Supplementary Table 2 . The specificity and effectiveness of the KLF14 antibody has been discussed in detail in previous work (Argmann et al. 2017).

\section{Immunohistochemistry}

A Vectastain Elite ABC Kit (Vector Laboratories, Burlingame, CA, USA) was used for in vivo detection of the immunolocalization of AR and KLF14 in formalinfixed and paraffin-embedded xenograft samples. Briefly, sections were deparaffinized, rehydrated and subjected to antigen retrieval in citrate buffer $\left(95^{\circ} \mathrm{C}, 15 \mathrm{~min}\right)$. Sections were then incubated in $3 \% \mathrm{H}_{2} \mathrm{O}_{2}$ solution in methanol at room temperature for $10 \mathrm{~min}$ to block endogenous peroxidase activity, followed by incubation overnight at $4^{\circ} \mathrm{C}$ with different primary antibodies (Supplementary Table 2). Immunostaining signals were finally developed according to the Vector Laboratories instructions.

\section{Chromatin immunoprecipitation (ChIP) and double ChIP}

LNCaP/DDK-KLF14 cells were challenged for $15 \mathrm{~min}$ with $1 \mathrm{mmol} / \mathrm{L}$ of $\mathrm{H}_{2} \mathrm{O}_{2}$, and cells were then crosslinked with $1 \%$ formaldehyde and sonicated. Soluble chromatin was immunoprecipitated and subjected to ChIP and double ChIP assays, as described in detail in our previous work (Zhang et al. 2012). Primers used for ChIP and double ChIP were listed in Supplementary Table 1.

\section{In vivo inhibition of HO-1 activity}

LNCaP-R cells were resuspended in PBS and $0.1 \mathrm{~mL}$ of cell suspension $\left(1 \times 10^{6}\right.$ cells $\left./ \mathrm{mL}\right)$ and were then injected into left flanks of castrated male nude mice. On the second day after cell inoculation, zinc protoporphyrin (ZnPP) IX from Sigma-Aldrich was dissolved in $0.25 \mathrm{M} \mathrm{NaOH}$ and the final concentration was adjusted to $10 \mu \mathrm{g} / \mu \mathrm{L}$ (Hirai et al. 2007). For administration to mice, the stock solutions were finally diluted with PBS by $1 \%(\mathrm{v} / \mathrm{v})$ for $20 \mu \mathrm{g} / \mathrm{mouse}$ dosage. Nude mice were treated intraperitoneally with ZnPPIX (10 mg/kg/day) or PBS vehicle control on daily basis. The volume changes of tumor xenografts were recorded every week. At the end of 6 weeks after LNCaP-R cells inoculation, mice were killed and the HO-1 activity in tumor xenografts were assayed as described below.

\section{Determination of HO-1 activity}

Tumor xenografts were homogenized in ice-cold homogenate buffer (20 mM PBS buffer, $250 \mathrm{mM}$ sucrose, $2 \mathrm{mM}$ EDTA, $2 \mathrm{mM}$ phenylmethylsulfonyl fluoride and $10 \mu \mathrm{g} / \mathrm{mL}$ leupeptin) as described elsewhere (Araujo et al. 2013). After centrifuge, the resultant supernatant was collected and subjected to the measurement of HO-1 activity using Human Heme Oxygenase 1 ELISA Kit (Abcam). Final spectrophotometry was developed in triplicate at $450 \mathrm{nM}$, as per the manufacturer's instructions.

\section{Statistical analysis}

Statistical analyses were performed using SPSS 15.0. Statistical comparisons and analyses were performed by either Student's $t$ test or one-way ANOVA (Prism 5.00, GraphPad Software Inc.) followed by Tukey post hoc analyses. Results are presented as mean \pm s.E.M. and $P<0.05$ was considered statistically significant.

\section{Results}

\section{KLF14 upregulation is associated with the pathogenesis of CRPC}

The present study was initially designed to uncover novel mechanisms underlying the potential involvement of KLF14 in CRPC. For this purpose, we established the expression profiles of KLF14 in human PCa cells. Genetic backgrounds of different PCa cells were provided in Fig. 1A. Persistent KLF14 expression was detected in all cell lines by means of immunoblotting. However, KLF14 expression was relatively low in RWPE- 1 and LNCaP cells, with higher expression observed in CWR-R1, 22RV1, PC3 and DU145 cells (Fig. 1A). Such a protein expression profile was confirmed by RT-qPCR at the mRNA level (Fig. 1B). Next, we established the castration-resistant sublines (LNCaP-R)
(C) 2019 Society for Endocrinology Published by Bioscientifica Ltd. Printed in Great Britain 
according to a previously validated protocol (Ning et al. 2016). Interestingly, when LNCaP became castration resistant, as evidenced by the persistent high production of intracellular PSA and AR in the androgen-depleted medium, LNCaP-R cells showed an evoked level of KLF14 expression (Fig. 1C, D and E). To further provide the in vivo evidence for the association of KLF14 upregulation with CRPC pathogenesis, we employed a CRPC patientderived xenograft model, which progresses with elevated expression levels of PSA and AR (Supplementary Fig. 1), mimicking the clinical behavior of CRPC to the maximum extent (Terada et al. 2010). The xenograft tissues were harvested during androgen-dependent growth $(\mathrm{AD})$, castration-induced regression nadir (RN) and castration-resistant regrowth (CR) stages (Fig. 1F). The nuclear expression of AR abated from the AD stage to the RN stage, but fully recovered at the CR stage (Fig. 1G), mimicking the clinical pathogenesis of CRPC. In line with these observations, KLF14 expression was dramatically upregulated with the progression of castration resistance in the xenografts (Fig. 1H and I). Taken together, these results suggest that KLF14 deregulation correlates to CRPC development.

\section{Oxidative stress induces KLF14 expression}

Because castration induces oxidative stress in vivo, understanding how reactive oxygen species (ROS) regulates the cellular processes controlling malignant transformation holds a lot of promise in combating CRPC (Zhang et al. 2014b). To this end, we treated LNCaP and PC3 cells with $\mathrm{H}_{2} \mathrm{O}_{2}$ that partially mimic cellular events after castration. $\mathrm{H}_{2} \mathrm{O}_{2}$ stimulation led to increased levels of KLF14 mRNA in a dose- and time-dependent manner, regardless of cell types (Fig. 2A, B, C and D). We then asked whether oxidative stress other than $\mathrm{H}_{2} \mathrm{O}_{2}$ can cause KLF14 activation, by treating cells with diamide that oxidizes cellular thiols and provokes a rapid decrease in cellular glutathione, hence causing oxidative stress (Zhang et al. 2014b). As expected, diamide treatment also caused KLF14 activation in a dose-dependent manner. In agreement, co-incubation with diphenyleneiodonium chloride (an inhibitor of oxidative stress) effectively abolished diamide-elicited KLF14 activation (Fig. 2E and F). To gain mechanistic insights into the regulation of KLF14 expression, we stimulated PCa cells for $15 \mathrm{~min}$ with $1 \mathrm{mmol} / \mathrm{L}$ of $\mathrm{H}_{2} \mathrm{O}_{2}$, in the presence of different pathway inhibitors including LY294002 (PI3K/AKT), U0128 (p42/p44 MAPK), SB203580 (p38 MAPK), SP600125 (JNK), WZ4003 (AMPK) and Go6976 (PKC).
Concomitant incubation with LY294002, U0128, WZ4003 and Go6976 significantly reduced the KLF14 upregulation induced by $\mathrm{H}_{2} \mathrm{O}_{2}$ (Fig. $2 \mathrm{G}$ ), suggesting that KLF14 upregulation by oxidative stress may be dependent on PI3K/AKT, p42/p44 MAPK, AMPK and PKC activation.

\section{Endogenous KLF14 protects PCa cells under androgen-depleted conditions}

Having established the association between KLF14 expression and CRPC progression, we then determined the malignant status of CWR-R1 and DU145 cells upon inhibition of KLF14 with shRNA. Treatment of CWR-R1 cells with 25 or $50 \mathrm{nmol} / \mathrm{L}$ of KLF14 shRNA both led to reduced levels of KLF14 expression (Fig. 3A and B), so we selected $25 \mathrm{nmol} / \mathrm{L}$ of KLF1 4 shRNA for further studies. The androgen-depleted condition (FBS-CS culture)-induced growth inhibition was significantly enhanced in the CWR-R1 and DU145 cells depleted of endogenous KLF14, compared to that in cells transfected with Ctrl shRNA or cells cultured in normal medium (Fig. 3C). Subsequent ELISA methods revealed that KLF14 knockdown in CWRR1 and DU145 cells led to notable increase of apoptosis in the presence of FBS-CS culture (Fig. 3D). Consistently, lower colony formation efficiency was after FBS-CS incubation in CWR-R1 and DU145 cells stably transfected with KLF14 shRNA (Fig. 3E). Such growth inhibition by KLF14 knockdown was also observed in xenograft models in castrated immunodeficient mice (Fig. 3F). The above-mentioned phenotype was further verified in and DU145 cells (Fig. 3G, H, I, J, K and L). Thus, repression of KLF14 expression compromises the proliferation and clonogenicty of PCa cells under androgen-depleted conditions.

\section{Ectopic overexpression of exogenous KLF14 potentiates androgen-independence in LNCaP cells}

To directly ask whether KLF14 contributes to CRPC progression, as inferred from the above-mentioned lossof-function analysis, we stably overexpressed pcDNA3.1+DDK-KLF14 in LNCaP cells (Fig. 4A) and then cultured these cells in medium containing FBS-CS. FBS-CSinduced growth inhibition was significantly attenuated in LNCaP/DDK-KLF14 cells compared with the pcDNA3.1+ vector-transfected cells (Fig. 4B). Conversely, FBS-CSinduced apoptosis was partially but effectively attenuated in LNCaP/DDK-KLF14 cells (Fig. 4C). In agreement, the colony formation efficiency (Fig. 4D) and formation of xenograft tumors in castrated immunodeficient mice (c) 2019 Society for Endocrinology Published by Bioscientifica Ltd. Printed in Great Britain 
A

\begin{tabular}{|c|c|c|}
\hline Cell line & $\mathbf{A R}$ & Growh characteristic \\
\hline RWPE:-1 & + & Androgen-dependent \\
\hline INC2 & + & Androgen-dependent \\
\hline CWR-R1 & + & Androsen independent \\
\hline 22RV1 & - & Androsen-inde pendent \\
\hline PC3 & - & Androgen-independent \\
\hline Do145 & - & Androgen-independen: \\
\hline
\end{tabular}

E

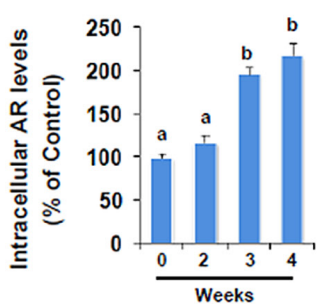

G

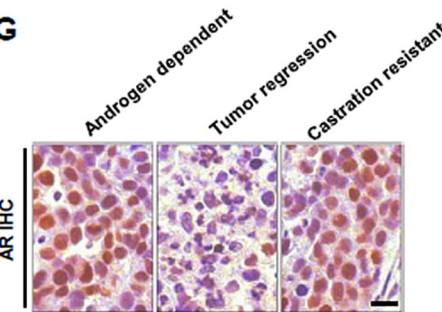

B
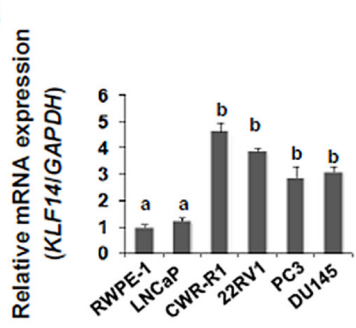

C

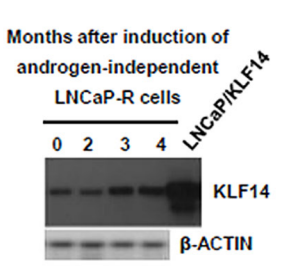

D
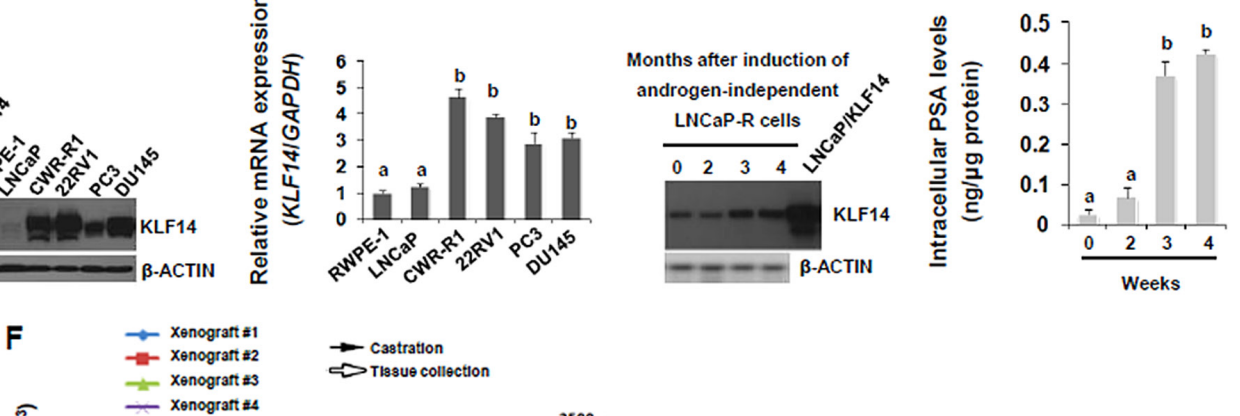

$\rightarrow$ Castration

$\approx$ Trsue collection
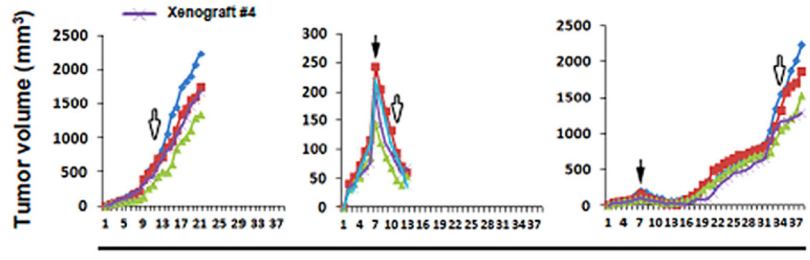

Weeks

$\mathrm{H}$

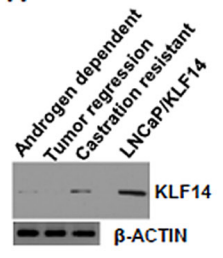

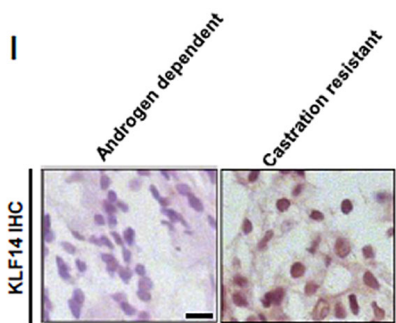

Figure 1

Stimulation of KLF14 expression during the castration-resistant progression of PCa cells. (A) Left panel: Genetic backgrounds of PCa cells used in this study. Right panel: Relative expression of KLF14 in different PCa cells was determined using immunoblotting. Densitometric scanning of immunoblots was performed in which the level of a target protein was normalized against the protein level in RWPE-1 cells, which was arbitrarily set at 1. (B) KLF14 expression in different PCa cells was evaluated using RT-qPCR. Different superscript letters denote groups that are statistically different $(P<0.05)$. (C) KLF14 expression along the generation of the castration-resistant LNCaP-R cells was assayed by immunoblotting. (D) Intracellular PSA levels of LNCaP-R cells were measured using a commercially available ELSIA kit. Different superscript letters denote groups that are statistically different $(P<0.05)$. (E) Intracellular AR levels of LNCaP-R cells were measured using a commercially available ELSIA kit. Different superscript letters denote groups that are statistically different $(P<0.05)$. (F) Sequential changes in xenograft tumor volume was recorded every week at the AD, castration-induced regression nadir (RN), and CR stages $(n=4)$, respectively. (G) AR immunohistochemistry at $A D$, RN and CR stages of xenograft tumors. Bar $=25 \mu \mathrm{m}$. (H) Immunoblotting analysis of KLF14 expression in different xenograft tumors. (I) KLF14

immunohistochemistry in different xenograft tumors. Bar $=50 \mu \mathrm{m}$. A full-colour version of this figure is available at https://doi.org/10.1530/ERC-18-0383.

(Fig. 4E) were substantially augmented in LNCaP cells by KLF14 overexpression. Therefore, these data demonstrate that KLF14 directly promotes castration resistance in AD PCa cells.

\section{KLF14 protects PCa cells from oxidative stress via restoring cellular redox balance}

Because castration dramatically increases oxidative stress of the prostate, and KLF14 elevation leads to constitutive resistance against castration-induced cell death, we the asked whether oxidative stress and KLF14 signaling functions in a reciprocal manner. To this end, we measured the effects of KLF14 alteration on the cellular sensitivity to two different oxidizing agents, namely $\mathrm{H}_{2} \mathrm{O}_{2}$ and paraquat. As shown in cell viability assays, the pcDNA3.1+-DDK-KLF14/LNCaP cells were significantly more resistant to $\mathrm{H}_{2} \mathrm{O}_{2}$ insult, compared to the pcDNA3.1+ vector-transfected LNCaP cells. This protective effect appeared in a dose- and time-dependent manner (Fig. 5A and B). In contrast, KLF14 knockdown by stable shRNA transfection enhanced $\mathrm{H}_{2} \mathrm{O}_{2}$-impaired cell viability in DU145 cells over a wide range of doses (Fig. 5C) and stimulation durations (Fig. 5D). Paraquat induces the excessive generation of superoxide ions $\left(\mathrm{O}_{2}{ }^{-}\right)$, which are detoxified by a mechanism distinct from $\mathrm{H}_{2} \mathrm{O}_{2}$ (Bae et al. 2004). Interestingly, ectopic KLF14 overexpression led to more paraquat resistance in LNCaP cells (Fig. 5E), whereas KLF14 inhibition caused a significant reduction in cell viability in paraquat-treated DU145 cells (Fig. 5F). Thus, both exogenous and endogenous KLF14 protects PCa cells against distinct forms of oxidative stress. To rule out the (c) 2019 Society for Endocrinology Published by Bioscientifica Ltd. Printed in Great Britain 
possibility that the protective effects of KLF14 are limited to long-term assays, we tested the effect of transient expression of pcDNA3.1+-DDK-KLF14 on the response of LNCaP cells to $\mathrm{H}_{2} \mathrm{O}_{2}$. In accordance with the preceding phenotype in stable transfections, at $\mathrm{H}_{2} \mathrm{O}_{2}$ doses of 400-500 nmol/L, KLF14 transfection exhibited significant protective effects (Fig. 5G). Apparently, overexpression of KLF14 (by either stable or transient transfection) protects and inactivation of KLF14 by knockdown sensitizes PCa cells against oxidative stress. Because cellular response to oxidative stress depends essentially upon the redox balance, we explored the effect of KLF14 overexpression on the redox balance of LNCaP cells after treatment with different doses of $\mathrm{H}_{2} \mathrm{O}_{2}$ for $24 \mathrm{~h}$. In vector-transfected LNCaP cells, $\mathrm{H}_{2} \mathrm{O}_{2}$ induced a dose-dependent shift in the redox state to increased GSSG and decreased GSH levels. Contrarily, pcDNA3.1+-DDK-KLF14/LNCaP cells were able to maintain significantly higher ratios of GSH/GSSG over a wide range of $\mathrm{H}_{2} \mathrm{O}_{2}$ doses (Fig. $5 \mathrm{H}$ ), indicating that
KLF14 may enhance the antioxidant response upon oxidative stress.

\section{KLF14 regulates HO-1 expression at the transcriptional level}

To dissect the molecular mechanisms underlying the promoting effect of KLF14 on the antioxidant response, we examined the expression levels of a range of antioxidant genes in pcDNA3.1+-DDK-KLF14/LNCaP cells using RT-qPCR. These experiments revealed that KLF14 induced a 5.3-fold increase in expression of HMOX1 (Fig. 6A), the gene encoding heme oxygenase 1 (HO-1), a rate-limiting enzyme conferring cytoprotection against oxidative stress (Nitti et al. 2017). We confirmed the parallel upregulation of KLF14 and HO-1 expression in the CRPC patientderived xenograft model using immunoblotting analysis (Fig. 6B). More importantly, KLF14 overexpression resulted in a significant induction of HO-1 expression,
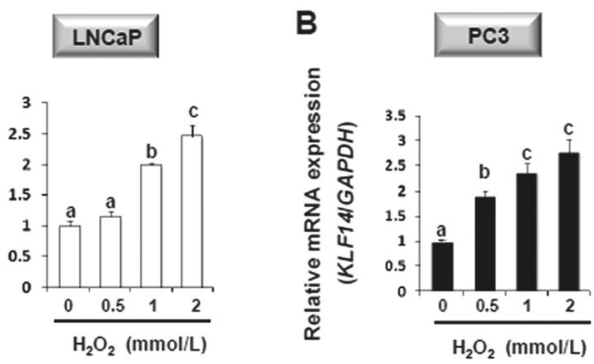

C
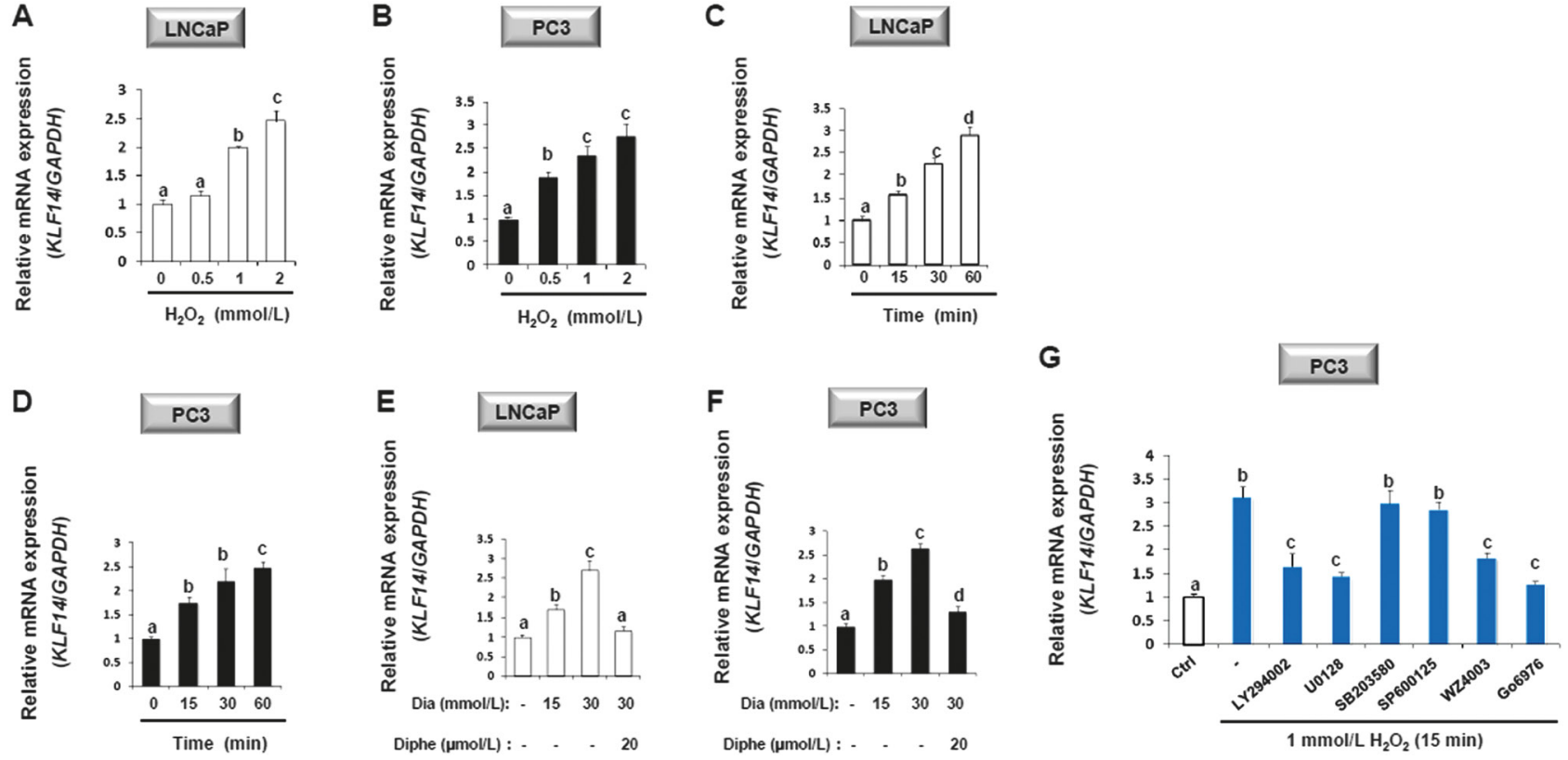

PC3

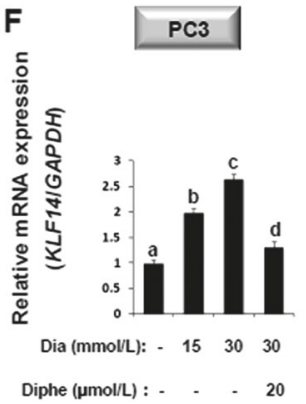

Figure 2

Regulation of KLF14 expression by oxidative stress. (A) LNCaP cells were incubated with different concentrations of $\mathrm{H}_{2} \mathrm{O}_{2}$ for 15 min, followed by RT-qPCR analysis of KLF14 expression. Different superscript letters denote groups that are statistically different $(P<0.05)$. (B) PC3 cells were incubated with different concentrations of $\mathrm{H}_{2} \mathrm{O}_{2}$ for $15 \mathrm{~min}$, followed by RT-qPCR analysis of $K L F 14$ expression. Different superscript letters denote groups that are statistically different $(P<0.05)$. (C) LNCaP cells were incubated with $1 \mathrm{mmol} / \mathrm{L}$ of $\mathrm{H}_{2} \mathrm{O}_{2}$ for different durations, followed by RT-qPCR analysis of $K L F 14$ expression. Different superscript letters denote groups that are statistically different $(P<0.05)$. (D) $P C 3$ cells were incubated with $1 \mathrm{mmol} / \mathrm{L}$ of $\mathrm{H}_{2} \mathrm{O}_{2}$ for different durations, followed by RT-qPCR analysis of KLF14 expression. Different superscript letters denote groups that are statistically different $(P<0.05)$. (E) LNCaP cells were incubated with different concentrations of diamide for $15 \mathrm{~min}$ in the presence or absence of $20 \mu \mathrm{mol} / \mathrm{L}$ of diphenyleneiodonium chloride, followed by RT-qPCR analysis of KLF14 expression. Different superscript letters denote groups that are statistically different (P<0.05). (F) PC3 cells were incubated with different concentrations of diamide for $15 \mathrm{~min}$ in the presence or absence of $20 \mu \mathrm{mol} / \mathrm{L}$ of diphenyleneiodonium chloride, followed by RT-qPCR analysis of KLF14 expression. Different superscript letters denote groups that are statistically different $(P<0.05)$. (G) RT-qPCR showing KLF14 expression in PC3 cells induced with $\mathrm{H}_{2} \mathrm{O}_{2}(1 \mathrm{mmol} / \mathrm{L})$ for $15 \mathrm{~min}$, in the presence of different pathway inhibitors. Different superscript letters denote groups that are statistically different $(P<0.05)$. A full-colour version of this figure is available at https://doi.org/10.1530/ERC-18-0383.

https://erc.bioscientifica.com

https://doi.org/10.1530/ERC-18-0383
(C) 2019 Society for Endocrinology Published by Bioscientifica Ltd. Printed in Great Britain 
A

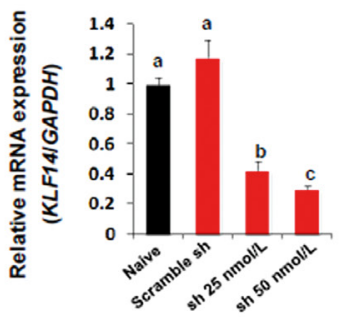

D
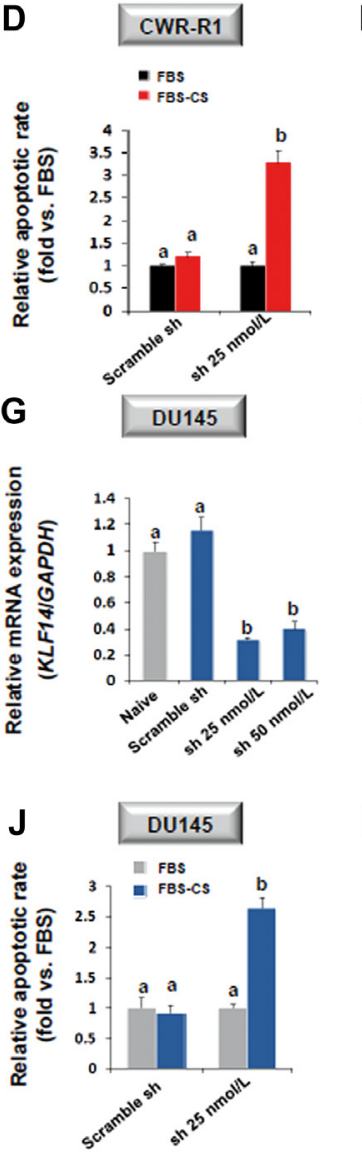

B

CWR-R1

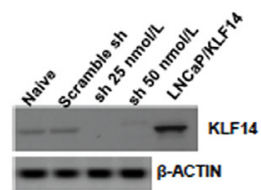

E

CWR-R1

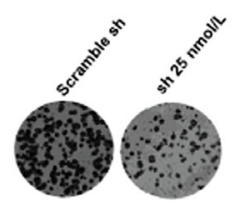

H

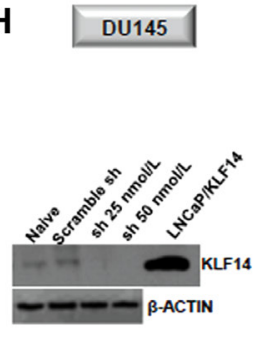

$\mathbf{F}$

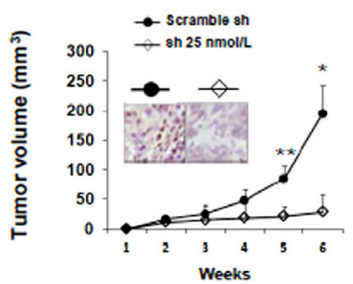

I

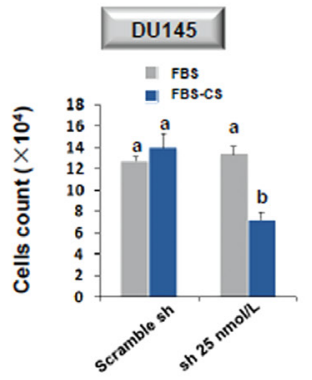

K

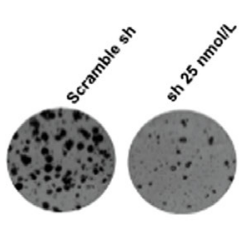

C
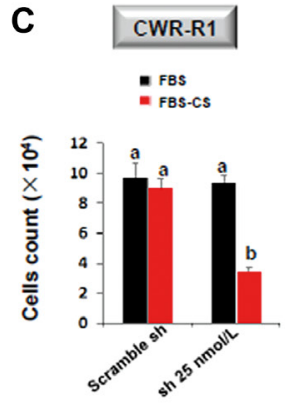

CWR-R1

$\mathbf{L}$

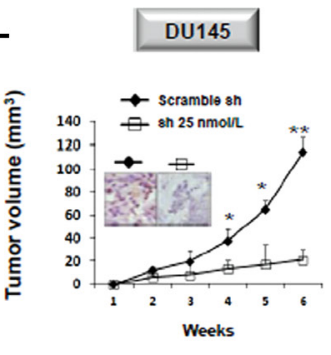

Figure 3

Repression of the castration-resistant progression in PCa cells by KLF14 inhibition. (A) KLF14 stable knockdown in CWR-R1 cells by shRNA treatment was validated using RT-qPCR. Different superscript letters denote groups that are statistically different $(P<0.05)$. (B) KLF14 stable knockdown in CWR-R1 cells by shRNA treatment was validated using immunoblotting. (C) CWR-R1 cells with different transfections were cultured for 3 days in media containing either 10\% FBS or 10\% FBS-CS, followed by Trypan blue staining and viable cells count. Different superscript letters denote groups that are statistically different $(P<0.05)$. (D) CWR-R1 cells with different transfections were cultured for 3 days in media containing either 10\% FBS or $10 \%$ FBS-CS, followed by apoptosis ELISA measurement. Different superscript letters denote groups that are statistically different $(P<0.05)$. (E) Anchorage-dependent clonogenic ability of CWR-R1 cells with different transfections was assessed using colony formation assay. (F) CWR-R1 cells with different transfections were injected into left flanks of castrated male nude mice. The inoculated cells were allowed to grow for 6 weeks until the tumors reached a volume of $\sim 100-250$ mm ${ }^{3}$. Tumor volume changes were recorded every week accordingly ( $n=5 /$ group, $* p<0.05, * \star p<0.01)$. Inserted is the immunohistochemical staining of KLF14 expression in xenografts at the end of 6 weeks after cell inoculation. (G) KLF14 stable knockdown in DU145 cells by shRNA treatment was validated using RT-qPCR. Different superscript letters denote groups that are statistically different $(P<0.05)$. (H) KLF14 stable knockdown in DU145 cells by shRNA treatment was validated using immunoblotting. (I) DU145 cells with different transfections were cultured for 3 days in media containing either $10 \%$ FBS or $10 \%$ FBS-CS, followed by Trypan blue staining and viable cells count. Different superscript letters denote groups that are statistically different $(P<0.05)$. (J) DU145 cells with different transfections were cultured for 3 days in media containing either $10 \%$ FBS or $10 \%$ FBS-CS, followed by apoptosis ELISA measurement. Different superscript letters denote groups that are statistically different $(P<0.05)$. (K) Anchorage-dependent clonogenic ability of DU145 cells with different transfections was assessed using colony formation assay. (L) DU145 cells with different transfections were injected into left flanks of castrated male nude mice. Tumor growth was examined as described above ( $n=5 /$ group, $* P<0.05, \star \star P<0.01)$. Inserted is the immunohistochemical staining of KLF14 expression in xenografts at the end of 6 weeks after cell inoculation. A full-colour version of this figure is available at https://doi.org/10.1530/ERC-18-0383.

(C) 2019 Society for Endocrinology Published by Bioscientifica Ltd. Printed in Great Britain 

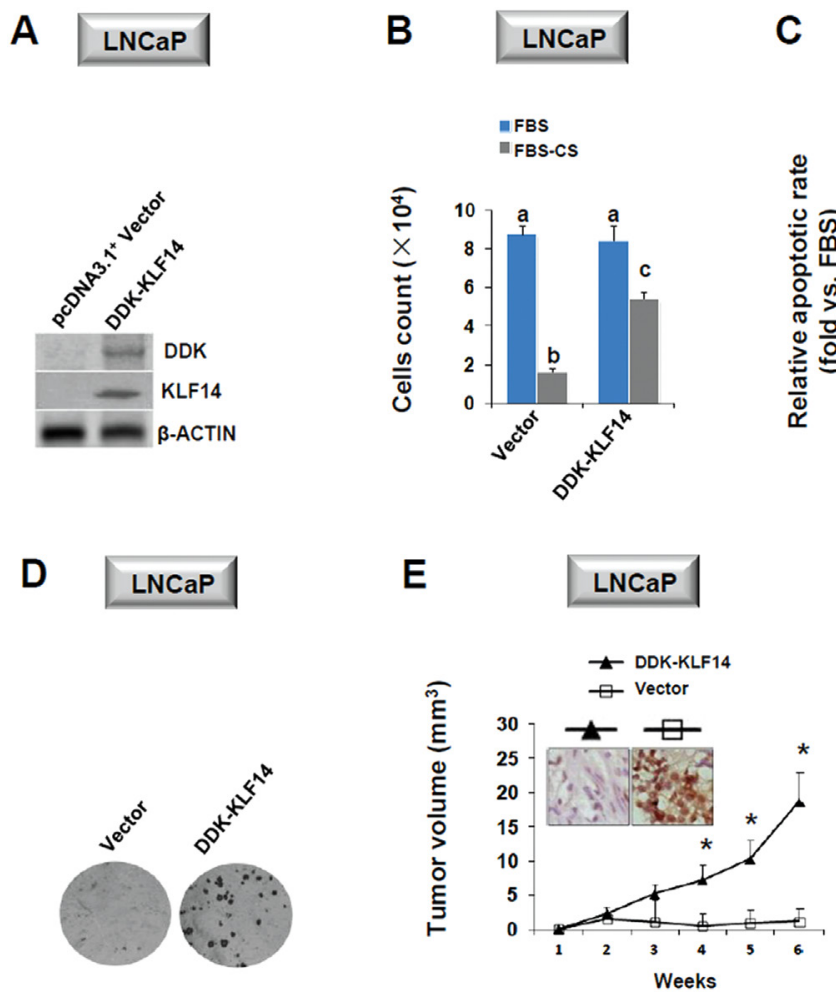

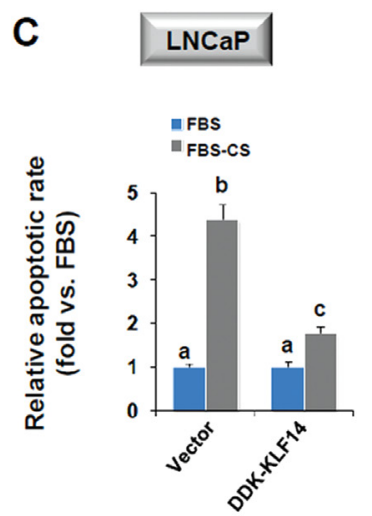

\section{Figure 4}

Potentiation of castration-resistant PCa cell growth by ectopic KLF14 overexpression. (A) Generation of LNCaP/DDK-KLF14 cells was validated using immunoblotting. (B) LNCaP cells with different transfections were cultured for 3 days in media containing either $10 \%$ FBS or $10 \%$ FBS-CS, followed by Trypan blue staining and viable cells count. Different superscript letters denote groups that are statistically different $(P<0.05)$. (C) LNCaP cells with different transfections were cultured for 3 days in media containing either $10 \%$ FBS or $10 \%$ FBS-CS, followed by apoptosis ELISA measurement. Different superscript letters denote groups that are statistically different $(P<0.05)$. (D) Anchoragedependent clonogenic ability of LNCaP cells with different transfections was assessed using colony formation assay. (E) LNCaP cells with different transfections were injected into left flanks of castrated male nude mice. Tumor growth was examined as described above ( $n=5$ /group, $\star P<0.05, * * P<0.01)$. Inserted is the immunohistochemical staining of KLF14 expression in xenografts at the end of 6 weeks after cell inoculation. A full-colour version of this figure is available at https://doi.org/10.1530 /ERC-18-0383. at both translational (Fig. 6C) and transcriptional levels (Fig. 6D). These results led us to investigate whether KLF14 functions as a transcriptional regulator of $H M O X 1$. As revealed by luciferase assays, transfection with pcDNA3.1+DDK-KLF14 significantly increased the HMOX1 reporter activity relative to control vector. This stimulatory effect was notably amplified by co-incubation with $\mathrm{H}_{2} \mathrm{O}_{2}$ or diamide. In good contrast, simultaneous treatment with diphenyleneiodonium chloride successfully abolished diamide-enhanced HMOX1 transactivation by KLF14 (Fig. 6E). Interestingly, subsequent evidence derived from analysis of the 5' flanking regions of human HMOX1 identified four sequences containing the conserved binding site of KLF14 (CACCC box, Fig. 6F). We then tested the hypothesis that KLF14 functions as a regulator of the putative binding sites in the HMOX1 promoter. ChIP assay revealed that KLF14 could bind the promoter region that harbors the proximal CACCC box (-645/-641) (Fig. 6G), demonstrating that this is a functional KLF14-binding site in the human $H M O X 1$ promoter. Consistently, this region (-645/-641) exhibited increased reporter activity relative to control vector and this stimulatory effect was significantly amplified by co-incubation with $\mathrm{H}_{2} \mathrm{O}_{2}$. Interestingly, mutation of the nt $-645 /-641$ site greatly reduced promoter activity (Fig. $6 \mathrm{H}$ and I). To extend our mechanistic understanding of how $\mathrm{H}_{2} \mathrm{O}_{2}$ regulates the transcription of HMOX1 through KLF14, we performed a double ChIP assay. Initial ChIP was done with anti-MTA2 antibody to immunoprecipitate the KLF14-bound DNA sequences, and the second ChIP was done with the anti-CBP or anti-p300 antibodies. We observed simultaneous co-association of KLF14 and CBP or p300 with the HMOX1 chromatin, and this recruitment was substantially augmented when $\mathrm{H}_{2} \mathrm{O}_{2}$ was added (Fig. 6J). Thus, together, these data demonstrate that KLF14 transcription factor is involved in the positive regulation of $H M O X 1$ transcription.

\section{HO-1 inhibition counteracts KLF14-induced castration resistance}

The preceding data have shown that upregulation of KLF14 expression induces HO-1 expression and resistance to oxidative stress, underscoring a fundamental role for KLF14 in the regulation of the antioxidant response under androgen-depleted conditions. In his regard, we finally initiated efforts toward evaluating the effect of HO-1 inhibition on KLF14-induced castration resistance. At the in vitro level, we probed the role of KLF14 targeting HO-1 in LNCaP cells stably expressing pcDNA3.1+-DDKKLF14. The transfection efficiency of HMOX1 shRNA in DDK-KLF14/LNCaP cells was over $80 \%$ but HO-1 silence exerted no effects on KLF14 expression level (Fig. 7A). Worthy to note, HO-1 knockdown successfully abolished KLF14 overexpression-induced cell proliferation (Fig. 7B) https://erc.bioscientifica.com

https://doi.org/10.1530/ERC-18-0383 (c) 2019 Society for Endocrinology Published by Bioscientifica Ltd. Printed in Great Britain 
A

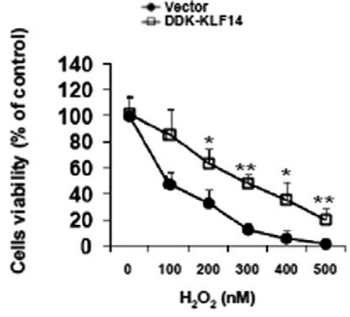

D
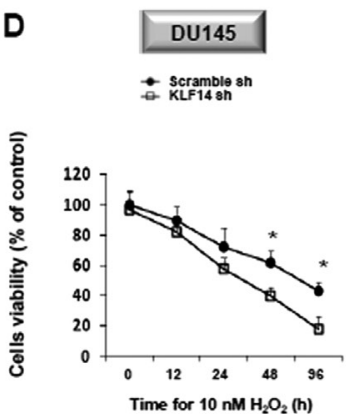

G

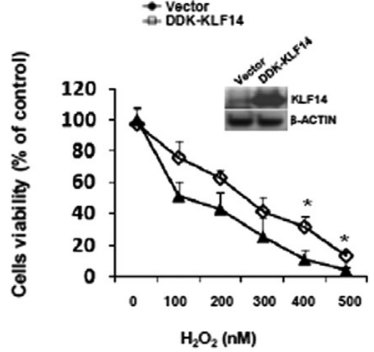

B

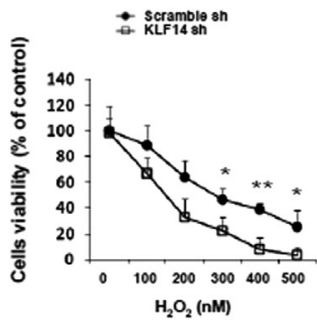

E
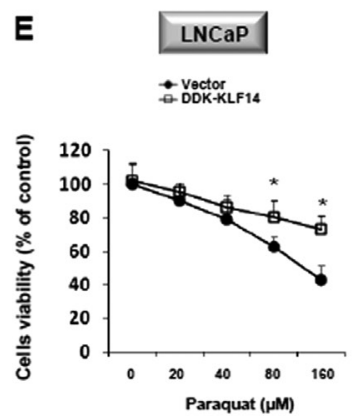

H
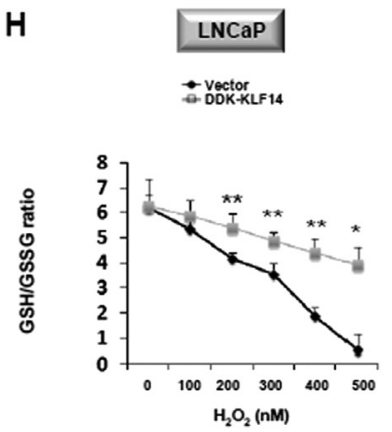

C

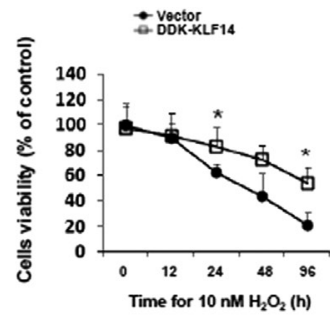

Figure 5

Conferring of PCa resistance to oxidative stress by KLF14. (A) LNCaP cells with different transfections were treated with different concentrations of $\mathrm{H}_{2} \mathrm{O}_{2}$ for $24 \mathrm{~h}$, followed by viability measurement $(* P<0.05, * * P<0.01)$. (B) LNCaP cells with different transfections were treated with $10 \mathrm{nM}$ of $\mathrm{H}_{2} \mathrm{O}_{2}$ for different durations, followed by viability measurement. (C) DU145 cells with different transfections were treated with different concentrations of $\mathrm{H}_{2} \mathrm{O}_{2}$ for $24 \mathrm{~h}$, followed by viability measurement. (D) DU145 cells with different transfections were treated with $10 \mathrm{nM}$ of $\mathrm{H}_{2} \mathrm{O}_{2}$ for different durations, followed by viability measurement. (E) LNCaP cells with different transfections were treated with different concentrations of paraquat for $24 \mathrm{~h}$, followed by viability measurement. (F) DU145 cells with different transfections were treated with different concentrations of paraquat for $24 \mathrm{~h}$, followed by viability measurement. (G) LNCaP cells were transiently transfected with pcDNA3.1+-DDKKLF14 or Ctrl vector as described in the Materials and methods section. $48 \mathrm{~h}$ later, cells were incubated with different concentrations of $\mathrm{H}_{2} \mathrm{O}_{2}$ for $24 \mathrm{~h}$, followed by viability measurement. $(\mathrm{H})$ LNCaP cells were transiently transfected with pcDNA3.1+-DDK-KLF14 or Ctrl vector as described above. $48 \mathrm{~h}$ later, cells were incubated with different concentrations of $\mathrm{H}_{2} \mathrm{O}_{2}$ for $24 \mathrm{~h}$, followed by measurement of GSH/GSSG ratio using a commercial kit. A full-colour version of this figure is available at https://doi.org/10.1530/ERC-180383.

and compromised KLF14-stimulated colony formation efficiency under androgen-depleted conditions (Fig. 7C). We then tried to solid this observation by examining the in vivo antitumor effect of ZnPPIX, a specific inhibitor of HO-1 (Fig. 7D) (Hirai et al. 2007). i.p. injection of ZnPPIX (30 mg/kg; once a day) suppressed the castration-resistant growth of LNCaP-R xenograft tumors, especially during the late stage of tumor development (Fig. 7E), which correlated well to a decrease of HO-1 activity in xenograft tumors (Fig. 7F). Notably, in vivo application of ZnPPIX effectively suppressed HO-1 expression but exerted no effects on KLF14 level in xenograft tumors (Supplementary Fig. 2). Thus, HO-1 antagonism with ZnPPIX might be an effective and achievable treatment modality for CRPC, in which KLF14 overexpression-induced castration-resistant progression.

\section{Discussion}

On the basis of the available data, we concluded that KLF14 expression is stimulated in castration-resistant PCa cells and xenograft tissues, which appears to be irrelevant to the AR pathway and may contribute to the oxidative stress-specific lineage characteristic of CRPC pathogenesis. Functionally, KLF14 upregulation potentiates the antioxidant response and cell growth under androgendepleted conditions. Mechanistically, in cooperation with CBP and p300, KLF14 positively regulates the antioxidant response in $\mathrm{PCa}$ cells by directly targeting HMOX1 transactivation (Fig. 8).

Known as an essential 'conductor of the metabolic syndrome orchestra', KLF14 involvement in cancer biology has just started to emerge. To this end, whether KLF14 functions as an oncogene or tumor suppressor gene has attracted much attention. Fan et al. have reported that KLF14 expression is significantly reduced in breast and colon cancer. By using KLF14 KO mice, they also demonstrate that KLF14 suppression serves as a potent mechanism leading to centrosome amplification and tumorigenesis. Thus, KLF14 functions fundamentally as a tumor suppressor in breast and colon cancer (Fan et al. 


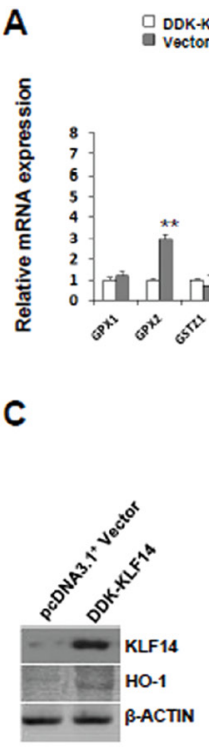

F

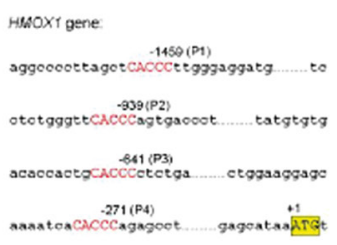

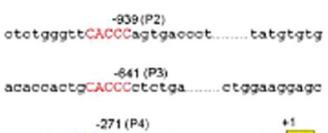

gacoggoogeggoto

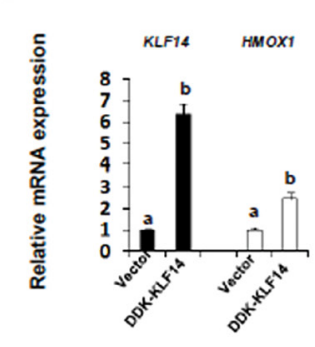

G
B

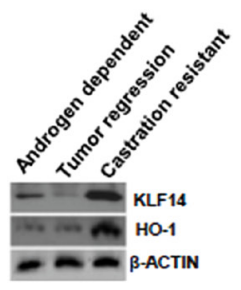

E

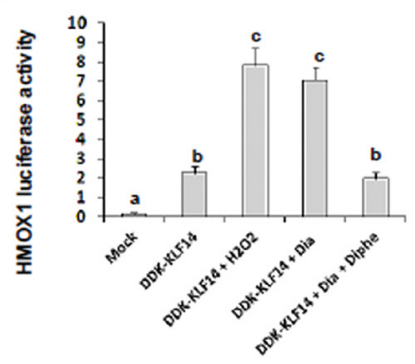

$\mathrm{H}$

HisOX1 gene:

aggcocettagctcaccettgggaggatg........to

otctgggtteacocagtgaccet ........tatgtgtg

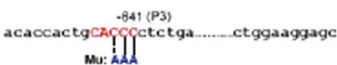

aaaatcacacceagagcet......gagcatan $\overline{A T G}$

gacoggcogeagetc
I

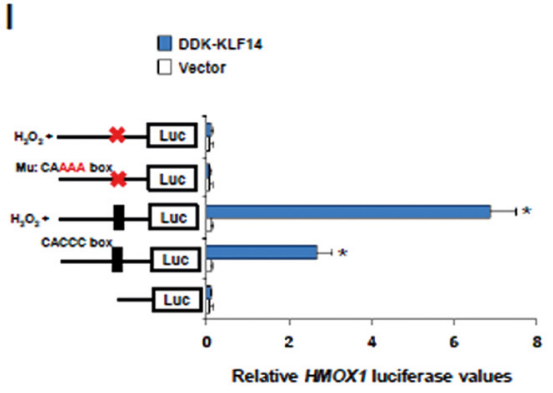

J

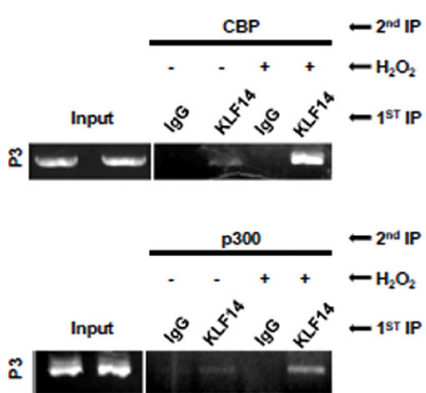

Figure 6

Positive regulation of HMOX1 transcription by KLF14. (A) Relative expression levels of different antioxidant genes in LNCaP/DDK-KLF14 and LNCaP/vector cells were evaluated using RT-qPCR ( $* P<0.05$ and $* * P<0.01$ compared to the values in LNCaP/vector cells). (B) Immunoblotting analysis of KLF14 and HO-1 expression in CRPC patient-derived xenograft model. (C) Immunoblotting analysis of KLF14 and HO-1 expression in LNCaP/DDK-KLF14 and LNCaP/ vector cells. (D) RT-qPCR analysis of KLF14 and HMOX1 levels in LNCaP/DDK-KLF14 and LNCaP/vector cells. Different superscript letters denote groups that are statistically different $(P<0.05)$. (E) The pGL4-Luc-HMOX1 reporter plasmid and pRL-TK Renilla reporter plasmid were co-transfected with pcDNA3.1+-DDK-KLF14 or pcDNA3.1+ vector into HeLa cells using FUGENE. $48 \mathrm{~h}$ later, cells were treated for $15 \mathrm{~min}$ with $1 \mathrm{mmol} / \mathrm{L}$ of $\mathrm{H}_{2} \mathrm{O}_{2}, 30 \mathrm{mmol} / \mathrm{L}$ of diamide or diamide plus $20 \mu \mathrm{mol} / \mathrm{L}$ of diphenyleneiodonium chloride, followed by luciferase activity measurements. Different superscript letters denote groups that are statistically different $(P<0.05)$. (F) Schematic of predicted KLF14 binding sites on the HMOX1 promoter region. (G) ChIP analysis showing recruitment of KLF14 onto a specific region of the HMOX1 promoter. (H) Schematic of the mutated KLF14 binding site on the HMOX1 promoter region. (I) The mutation of the putative KLF14-binding site on the promoter at -645/-641 was carried out by replacing CACCC with CAaaa using the QuikChange Site-Directed Mutagenesis Kit. The WT or mutated pGL4-Luc-HMOX1 reporter plasmid and pRL-TK Renilla reporter plasmid were co-transfected with pcDNA3.1+-DDK-KLF14 or pcDNA3.1+ vector into HeLa cells using FUGENE. $48 \mathrm{~h}$ later, cells were treated for $15 \mathrm{~min}$ with $1 \mathrm{mmol} / \mathrm{L}$ of $\mathrm{H}_{2} \mathrm{O}_{2}$. Relative luciferase activity was measured using a dual luciferase reporter assay kit. () Double ChIP analysis of KLF14-CBP/p300 complex onto the HMOX1 promoter in LNCaP/DDK-KLF14 cells upon challenge for $15 \mathrm{~min}$ with $1 \mathrm{mmol} / \mathrm{L}$ of $\mathrm{H}_{2} \mathrm{O}_{2}$. A full-colour version of this figure is available at https://doi. org/10.1530/ERC-18-0383. 


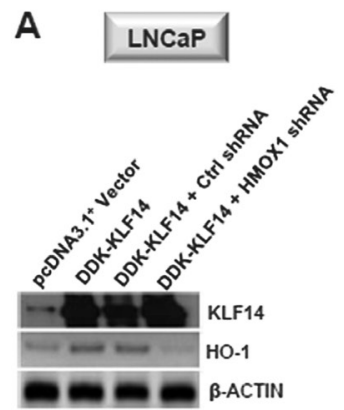

B

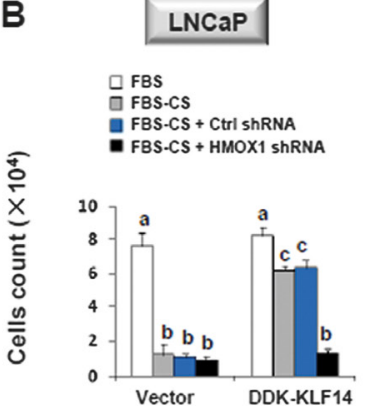

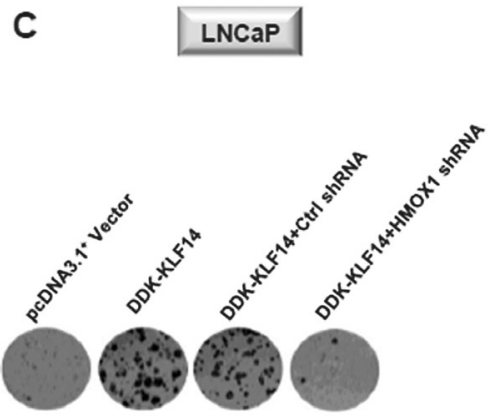
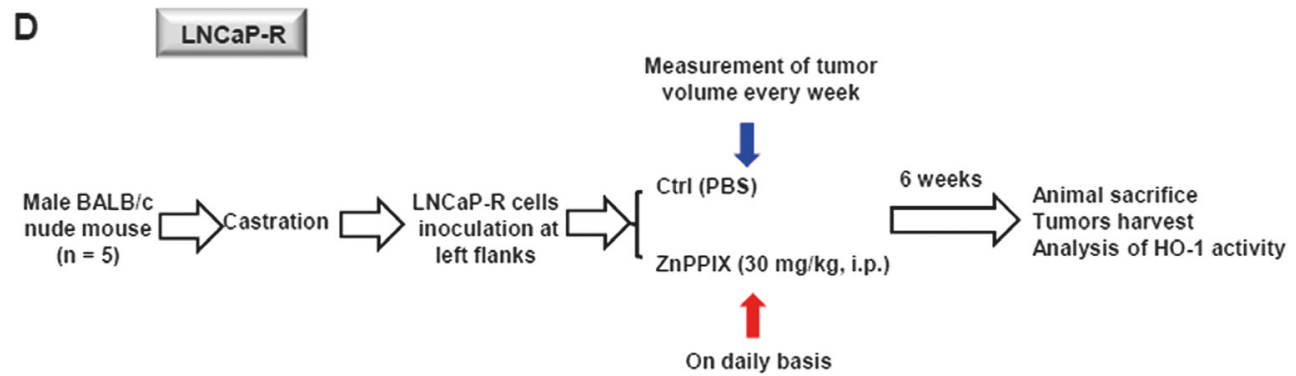

E
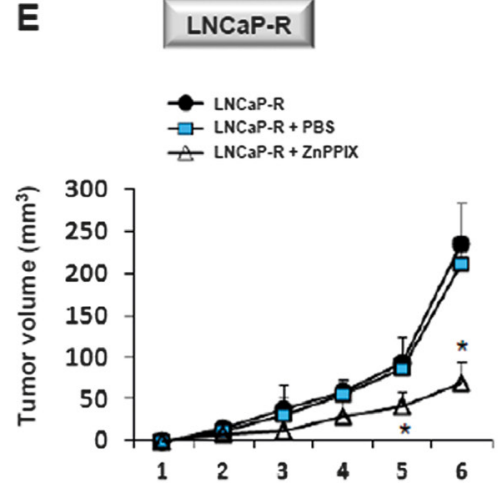
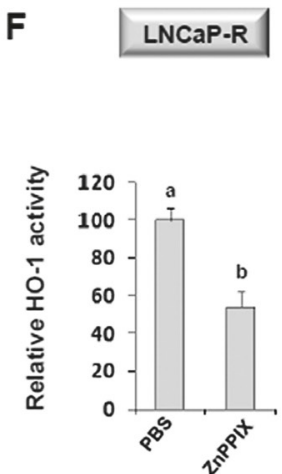

\section{Figure 7}

Therapeutic effectiveness of in vivo application of HO-1 inhibitor against castration-resistant PCa cell growth. (A) LNCaP/DDK-KLF14 cells were transiently transfected with HMOX1 shRNA or Ctrl shRNA. $48 \mathrm{~h}$ later, cells were harvested and subjected to immunoblotting analysis. (B) LNCaP cells with different transfections were cultured for 3 days in media containing either $10 \%$ FBS or $10 \%$ FBS-CS, followed by Trypan blue staining and viable cells count. Different superscript letters denote groups that are statistically different $(P<0.05)$. (C) Anchorage-dependent clonogenic ability of LNCaP cells with different transfections was assessed using colony formation assay. (D) Schematic representation of the experimental procedure for in vivo application of HO-1 inhibitor (ZnPPIX) in the LNCaP-R cells-derived tumor xenograft model. (E) LNCaP-R cells-derived tumor xenograft model was established as described in 'Materials and methods' section. Nude mice were treated intraperitoneally with ZnPPIX (10 mg/kg/day), or PBS vehicle control on daily basis. The volume changes of tumor xenografts were recorded every week ( $* P<0.05$ ). (F) Relative HO- 1 activity was measured in LNCaP-R cells-derived tumor xenografts using a commercial ELISA kit. Different superscript letters denote groups that are statistically different $(P<0.05)$. A full-colour version of this figure is available at https://doi.org/10.1530/ERC-18-0383.

2015). In contrast, in thyroid cancer, KLF14 expression has been shown to be upregulated compared with normal thyroid tissue. Knockdown of KLF14 expression results in reduced cell proliferation, G1-phase arrest, and increased apoptosis. Therefore, thyroid-originated KLF14 is an oncogene essential for cancer cell survival (Boot et al.
2016). These conflicting results strongly suggest that KLF14 may exhibit a dual function in response to distinct cell context depending upon the state of cell malignancy.

Evidence from both experimental and clinical studies have confirmed that castration, the major approach for treatment of late stage PCa, notably enhances oxidative
(C) 2019 Society for Endocrinology Published by Bioscientifica Ltd. Printed in Great Britain 


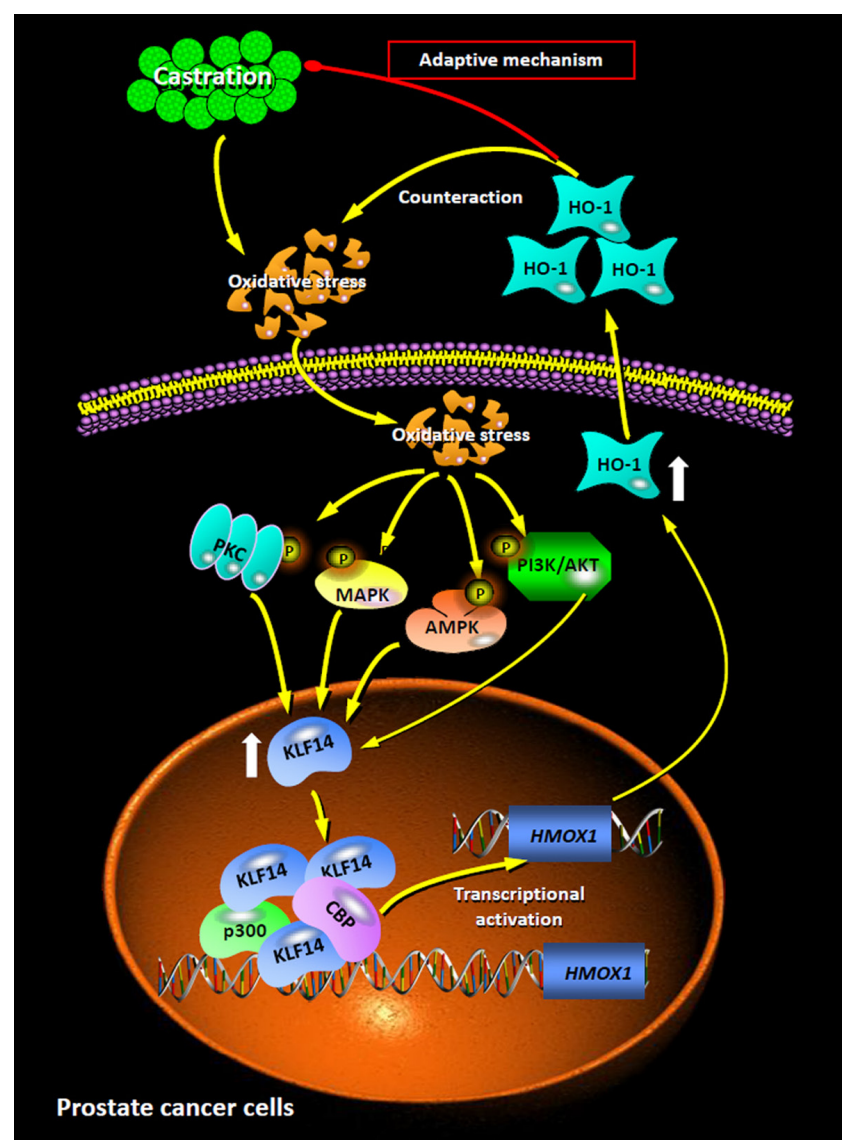

Figure 8

Summary diagram of the possible mechanisms related to KLF14 function contributing to promotion of the antioxidant response via transcriptional regulation of $\mathrm{HO}-1$ expression during castration-resistant $\mathrm{PCa}$ progression. A full-colour version of this figure is available at https://doi. org/10.1530/ERC-18-0383.

stress in prostatic cells. The latter in turn contribute tremendously to the development and progression of CRPC (Shiota et al. 2010, 2011). Therefore, it is logical that an impaired antioxidative capacity should be expected along the pathogenesis of CRPC. Nevertheless, the expression of many antioxidant genes has so far been found to be upregulated in CRPC. For instance, ADTinduced ROS enhances the expression and activity of NF-E2 related factor 1 and 2 (namely Nrf1 and Nrf2), two essential transcriptional factors governing the expression of numerous antioxidant genes. The resultant upregulation in selective antioxidant protein expression is believed to be associated with increased tumor survival under androgen-deprived conditions, thus promoting CRPC progression (Schultz et al. 2010). Similarly, expression of the antioxidant proteins Prx-1 and Txn-1 has been shown to be significantly stimulated in castration-resistant C4-2B cells than in AD LNCaP cells (Schultz et al. 2010).
It is reasoned that in concert with oxidative stress, differential antioxidant signaling pathways also help to regulate the aggressive behavior of CRPC cells. Our findings extend these knowledge by identifying KLF14 as a potent protector against oxidant toxicity by augmenting the antioxidant defenses (e.g., elevated expression of HO-1 and enhanced production of GSH). Given that ROS is detrimental to both normal and cancer cells, advanced PCa cells must develop mechanisms to get adapted to hypoxia and conditions of high oxidative stress. In favor of this hypothesis, intracellular ROS levels, along with GSTM3 expression (an enzyme functions in the detoxification of products of oxidative stress by conjugation with glutathione), have been reported to be induced simultaneously in castration-resistant and enzalutamide-resistant PCa cells (Shiota et al. 2017). These findings together suggest that a proper balance between oxidative stress and antioxidant pathways is absolutely required for CRPC pathogenesis. In this regard, the increased expression of KLF14 may entitle the castration-resistant $\mathrm{PCa}$ cells more equipped for constitutive modification of antioxidant signaling, thereby enhancing the aggressive phenotype of these cells.

Another relevant intriguing question addressed by the current study was how KLF14 regulates oxidative stress-elicited antioxidant response. We show that KLF14 activates $H M O X 1$ transcription by directly binding its chromatin and transient knockdown of HMOX1 is sufficient to overcome KLF14 overexpression-potentiated PCa cell growth under androgen-depleted conditions, indicating that KLF14 upregulation may promote uncontrolled HO-1-directed antioxidant response and thus promotes castration resistance. The upregulation of HO-1 is one of the most important mechanisms of cell adaptation to stress. HO- 1 induction has been frequently correlated with tumor growth, aggressiveness, metastatic and poor prognosis in lung, pancreatic, prostate, colorectal, ovarian cancer, melanoma, and hepatoma (Loboda et al. 2015). In particular, anticancer treatments such as chemo-, radio-, and photodynamic therapy all increase HO-1 expression (Nitti et al. 2017). Through the antioxidant and antiapoptotic properties of its metabolic products, HO-1 plays a key role in maintaining redox homeostasis during cancer progression (Loboda etal. 2016). Nevertheless, the transcriptional or posttranscriptional mechanisms responsible for controlling HO-1 expression in response to cytotoxic stress are poorly understood. Our findings extend these understanding by identifying KLF14 as a potent coactivator of HMOX1 transcription. Of note, multiple putative cis-regulatory elements have
(C) 2019 Society for Endocrinology Published by Bioscientifica Ltd. Printed in Great Britain 
been previously identified in the $H M O X 1$ promoter region including -146 to $-37 \mathrm{bp}$ for CREB (Astort et al. 2016), $-44 \mathrm{bp}$ for Nrf2 (Potteti et al. 2016) and -1036 to $+1 \mathrm{bp}$ for Sp1 and p53 (Tung et al. 2015). In contrast, the promoter region of HMOX1 bound by KLF14 ( -645 to $-641 \mathrm{bp}$ ) was not included in the above-mentioned cis-acting elements. These results collectively broaden our understanding of the diversity of the transcriptional regulation sites of HMOX1 expression.

Previous study has shown that the HO-1-specific antagonist, ZnPPIX, inhibits tumor growth of LL/2 lung cancer in C57BL mice (Hirai et al. 2007). The present study is the first report demonstrating that ZnPPIX reduces the castration-resistant progression of $\mathrm{PCa}$ cells induced without changing the high level of KLF14 expression. Given that LNCaP-R cells are AR-positive PCa cells with high KLF14 expression, our data indicate that HO-1 antagonism might have significant antitumor effects against CRPC.

In summary, we have demonstrated that KLF14 directly regulates $H M O X 1$ transactivation and potentiates resistance against androgen-depleted conditions by enhancing antioxidant response in PCa cells. Furthermore, we show that ZnPPIX, a pharmacological inhibitor of HO-1, attenuates castration-resistant progression. Overall, the work presented here identified a critical role of KLF14/HO-1 cascade, both as a target and as a modifier of the oxidative stress signaling in conferring an optimal adaptive mechanism during the pathogenesis of CRPC.

\section{Supplementary data}

This is linked to the online version of the paper at https://doi.org/10.1530/ ERC-18-0383.

\section{Declaration of interest}

The authors declare that there is no conflict of interest that could be perceived as prejudicing the impartiality of the research reported.

\section{Funding}

This work was supported by the National Natural Science Foundation of China (NSFC) $(31671198,31271248)$ and Key Research and Development Program of Shaanxi Province (2017SF-193).

\section{Acknowledgments}

The authors are grateful to Dr Yao-ni Li and Hai-feng Gao (Department of Clinical Laboratory, Baoji Center Hospital, People's Republic of China) and Dr Yuan Cai and Su Zheng (Department of Pathology, Baoji Center Hospital,
People's Republic of China), for their generous and careful assistance during the preparation of the manuscript.

\section{References}

Araujo EC, Barbosa BF, Coutinho LB, Barenco PV, Sousa LA, Milanezi CM, Bonfa G, Pavanelli WR, Silva JS, Ferro EA, et al. 2013 Heme oxygenase- 1 activity is involved in the control of Toxoplasma gondii infection in the lung of $\mathrm{BALB} / \mathrm{C}$ and $\mathrm{C} 57 \mathrm{BL} / 6$ and in the small intestine of C57BL/6 mice. Veterinary Research 44 89. (https:// doi.org/10.1186/1297-9716-44-89)

Argmann CA, Violante S, Dodatko T, Amaro MP, Hagen J, Gillespie VL, Buettner C, Schadt EE \& Houten SM 2017 Germline deletion of Kruppel-like factor 14 does not increase risk of diet induced metabolic syndrome in male C57BL/6 mice. Biochimica et Biophysica Acta 1863 3277-3285. (https://doi.org/10.1016/j.bbadis.2017.09.021)

Astort F, Repetto EM, Rocha-Viegas L, Mercau ME, Puch SS, Finkielstein CV, Pecci A \& Cymeryng CB 2016 Role of CREB on heme oxygenase-1 induction in adrenal cells: involvement of the PI3K pathway. Journal of Molecular Endocrinology 57 113-124. (https://doi.org/10.1530/JME-16-0005)

Bacos K, Gillberg L, Volkov P, Olsson AH, Hansen T, Pedersen O, Gjesing AP, Eiberg H, Tuomi T, Almgren P, et al. 2016 Blood-based biomarkers of age-associated epigenetic changes in human islets associate with insulin secretion and diabetes. Nature Communications 7 11089. (https://doi.org/10.1038/ncomms11089)

Bae I, Fan S, Meng Q, Rih JK, Kim HJ, Kang HJ, Xu J, Goldberg ID, Jaiswal AK \& Rosen EM 2004 BRCA1 induces antioxidant gene expression and resistance to oxidative stress. Cancer Research 64 7893-7909. (https://doi.org/10.1158/0008-5472.CAN-04-1119)

Boot A, Oosting J, de Miranda NF, Zhang Y, Corver WE, van de Water B, Morreau H \& van Wezel T 2016 Imprinted survival genes preclude loss of heterozygosity of chromosome 7 in cancer cells. Journal of Pathology 240 72-83. (https://doi.org/10.1002/path.4756)

Civelek M, Wu Y, Pan C, Raulerson CK, Ko A, He A, Tilford C, Saleem NK, Stancakova A, Scott LJ, et al. 2017 Genetic regulation of adipose gene expression and cardio-metabolic traits. American Journal of Human Genetics 100 428-443. (https://doi.org/10.1016/j. ajhg.2017.01.027)

de Assuncao TM, Lomberk G, Cao S, Yaqoob U, Mathison A, Simonetto DA, Huebert RC, Urrutia RA \& Shah VH 2014 New role for Kruppel-like factor 14 as a transcriptional activator involved in the generation of signaling lipids. Journal of Biological Chemistry 289 15798-15809. (https://doi.org/10.1074/jbc.M113.544346)

Dong YS, Hou WG, Li Y, Liu DB, Hao GZ, Zhang HF, Li JC, Zhao J, Zhang S, Liang GB, et al. 2016 Unexpected requirement for a binding partner of the syntaxin family in phagocytosis by murine testicular Sertoli cells. Cell Death and Differentiation 23 787-800. (https://doi.org/10.1038/cdd.2015.139)

Fan G, Sun L, Shan P, Zhang X, Huan J, Li D, Wang T, Wei T, Gu X, Yao L, et al. 2015 Loss of KLF14 triggers centrosome amplification and tumorigenesis. Nature Communications 6 8450. (https://doi. org/10.1038/ncomms9450)

Ferraldeschi R, Welti J, Luo J, Attard G \& de Bono JS 2015 Targeting the androgen receptor pathway in castration-resistant prostate cancer: progresses and prospects. Oncogene 34 1745-1757. (https://doi. org/10.1038/onc.2014.115)

Guo Y, Fan Y, Zhang J, Lomberk GA, Zhou Z, Sun L, Mathison AJ, Garcia-Barrio MT, Zeng L, Li L, et al. 2015 Perhexiline activates KLF14 and reduces atherosclerosis by modulating ApoA-I production. Journal of Clinical Investigation 125 3819-3830. (https://doi. org/10.1172/JCI79048)

Hirai K, Sasahira T, Ohmori H, Fujii K \& Kuniyasu H 2007 Inhibition of heme oxygenase- 1 by zinc protoporphyrin IX reduces tumor growth https://erc bioscientifica com

https://doi.org/10.1530/ERC-18-0383
2019 Society for Endocrinology Published by Bioscientifica Ltd. Printed in Great Britain 
of LL/2 lung cancer in C57BL mice. International Journal of Cancer 120 500-505. (https://doi.org/10.1002/ijc.22287)

Li W, Zeng Y, Zhao J, Zhu CJ, Hou WG \& Zhang S 2014 Upregulation and nuclear translocation of testicular ghrelin protects differentiating spermatogonia from ionizing radiation injury. Cell Death and Disease 5 e1248. (https://doi.org/10.1038/cddis.2014.223)

Loboda A, Jozkowicz A \& Dulak J 2015 HO-1/CO system in tumor growth, angiogenesis and metabolism - targeting HO-1 as an antitumor therapy. Vascular Pharmacology 74 11-22. (https://doi. org/10.1016/j.vph.2015.09.004)

Loboda A, Damulewicz M, Pyza E, Jozkowicz A \& Dulak J 2016 Role of Nrf2/HO-1 system in development, oxidative stress response and diseases: an evolutionarily conserved mechanism. Cellular and Molecular Life Sciences 73 3221-3247. (https://doi.org/10.1007/s00018-016-2223-0)

Long BJ, Grigoryev DN, Nnane IP, Liu Y, Ling YZ \& Brodie AM 2000 Antiandrogenic effects of novel androgen synthesis inhibitors on hormone-dependent prostate cancer. Cancer Research 60 6630-6640.

Ning P, Zhong JG, Jiang F, Zhang Y, Zhao J, Tian F \& Li W 2016 Role of protein $\mathrm{S}$ in castration-resistant prostate cancer-like cells. EndocrineRelated Cancer 23 595-607. (https://doi.org/10.1530/ERC-16-0126)

Nitti M, Piras S, Marinari UM, Moretta L, Pronzato MA \& Furfaro AL 2017 HO-1 induction in cancer progression: a matter of cell adaptation. Antioxidants 6 E29. (https://doi.org/10.3390/antiox6020029)

Potteti HR, Tamatam CR, Marreddy R, Reddy NM, Noel S, Rabb H \& Reddy SP 2016 Nrf2-AKT interactions regulate heme oxygenase 1 expression in kidney epithelia during hypoxia and hypoxiareoxygenation. American Journal of Physiology: Renal Physiology $\mathbf{3 1 1}$ F1025-F1034. (https://doi.org/10.1152/ajprenal.00362.2016)

Qi J, Tripathi M, Mishra R, Sahgal N, Fazli L, Ettinger S, Placzek WJ, Claps G, Chung LW, Bowtell D, et al. 2013 The E3 ubiquitin ligase Siah2 contributes to castration-resistant prostate cancer by regulation of androgen receptor transcriptional activity. Cancer Cell 23 332-346. (https://doi.org/10.1016/j.ccr.2013.02.016)

Schultz MA, Abdel-Mageed AB \& Mondal D 2010 The nrf1 and nrf2 balance in oxidative stress regulation and androgen signaling in prostate cancer cells. Cancers 2 1354-1378. (https://doi.org/10.3390/ cancers2021354)

Shiota M, Yokomizo A, Tada Y, Inokuchi J, Kashiwagi E, Masubuchi D, Eto M, Uchiumi T \& Naito S 2010 Castration resistance of prostate cancer cells caused by castration-induced oxidative stress through Twist1 and androgen receptor overexpression. Oncogene 29 237-250. (https://doi.org/10.1038/onc.2009.322)

Shiota M, Yokomizo A \& Naito S 2011 Oxidative stress and androgen receptor signaling in the development and progression of castration-resistant prostate cancer. Free Radical Biology and Medicine
51 1320-1328. (https://doi.org/10.1016/j.freeradbiomed. 2011.07.011)

Shiota M, Fujimoto N, Itsumi M, Takeuchi A, Inokuchi J, Tatsugami K, Yokomizo A, Kajioka S, Uchiumi T \& Eto M 2017 Gene polymorphisms in antioxidant enzymes correlate with the efficacy of androgen-deprivation therapy for prostate cancer with implications of oxidative stress. Annals of Oncology 28 569-575. (https://doi. org/10.1093/annonc/mdw646)

Terada N, Shimizu Y, Kamba T, Inoue T, Maeno A, Kobayashi T, Nakamura E, Kamoto T, Kanaji T, Maruyama T, et al. 2010 Identification of EP4 as a potential target for the treatment of castration-resistant prostate cancer using a novel xenograft model. Cancer Research 70 1606-1615. (https://doi.org/10.1158/0008-5472. CAN-09-2984)

Tung MC, Lin PL, Wang YC, He TY, Lee MC, Yeh SD, Chen CY \& Lee H 2015 Mutant p53 confers chemoresistance in non-small cell lung cancer by upregulating Nrf2. Oncotarget 6 41692-41705. (https://doi. org/10.18632/oncotarget.6150)

Twiddy AL, Leon CG \& Wasan KM 2011 Cholesterol as a potential target for castration-resistant prostate cancer. Pharmaceutical Research 28 423-437. (https://doi.org/10.1007/s11095-010-0210-y)

Yu L, Su YS, Zhao J, Wang H \& Li W 2013 Repression of NR4A1 by a chromatin modifier promotes docetaxel resistance in PC-3 human prostate cancer cells. FEBS Letters $\mathbf{5 8 7}$ 2542-2551. (https://doi. org/10.1016/j.febslet.2013.06.029)

Zhang S, Li W, Zhu C, Wang X, Li Z, Zhang J, Zhao J, Hu J, Li T \& Zhang Y 2012 Sertoli cell-specific expression of metastasis-associated protein 2 (MTA2) is required for transcriptional regulation of the follicle-stimulating hormone receptor (FSHR) gene during spermatogenesis. Journal of Biological Chemistry 287 40471-40483. (https://doi.org/10.1074/jbc.M112.383802)

Zhang C, Lai JH, Hu B, Zhang S, Zhao J \& Li W 2014a A chromatin modifier regulates Sertoli cell response to mono-(2-ethylhexyl) phthalate (MEHP) via tissue inhibitor of metalloproteinase 2 (TIMP2) signaling. Biochimica et Biophysica Acta 1839 1170-1182. (https://doi. org/10.1016/j.bbagrm.2014.08.006)

Zhang Z, Hou X, Shao C, Li J, Cheng JX, Kuang S, Ahmad N, Ratliff T \& Liu X 2014b Plk1 inhibition enhances the efficacy of androgen signaling blockade in castration-resistant prostate cancer. Cancer Research 74 6635-6647. (https://doi.org/10.1158/0008-5472.CAN-141916)

Zuo M, Xu X, Li T, Ge R \& Li Z 2016 Progress in the mechanism and drug development of castration-resistant prostate cancer. Future Medicinal Chemistry 8 765-788. (https://doi.org/10.4155/ fmc.16.12)

Received in final form 8 September 2018

Accepted 11 September 2018

Accepted Preprint published online 11 September 2018 (c) 2019 Society for Endocrinology Published by Bioscientifica Ltd. Printed in Great Britain 